\title{
Enhanced Endocannabinoid-Mediated Modulation of Rostromedial Tegmental Nucleus Drive onto Dopamine Neurons in Sardinian Alcohol-Preferring Rats
}

\author{
Diriam Melis, ${ }^{1}$ Claudia Sagheddu, ${ }^{1}$ Marta De Felice, ${ }^{1}$ Alberto Casti, ${ }^{1}$ Camilla Madeddu, ${ }^{1}$ Saturnino Spiga, ${ }^{2}$ \\ Anna Lisa Muntoni, ${ }^{3}$ Kenneth Mackie, ${ }^{4}$ Giovanni Marsicano, ${ }^{5,6}$ Giancarlo Colombo, ${ }^{3}$ Maria Paola Castelli, ${ }^{1}$ \\ and $\oplus^{\circ}$ Marco Pistis ${ }^{1,3}$ \\ ${ }^{1}$ Division of Neuroscience and Clinical Pharmacology, Department of Biomedical Sciences, University of Cagliari, 09042 Monserrato, Italy, ${ }^{2}$ Department of \\ Life and Environment Science, University of Cagliari, 09126 Cagliari, Italy, ${ }^{3}$ Neuroscience Institute, National Research Council of Italy, Section of Cagliari, \\ 09126 Cagliari Italy, ${ }^{4}$ Department of Psychological and Brain Sciences, Gill Center for Biomolecular Sciences, Indiana University of Bloomington, \\ Bloomington, Indiana 47405, ${ }^{5}$ INSERM, U862 NeuroCentre Magendie, Endocannabinoids and Neuroadaptation, 33077 Bordeaux, France, and ${ }^{6}$ University \\ of Bordeaux, NeuroCentre Magendie U862, 33077 Bordeaux, France
}

The progressive predominance of rewarding effects of addictive drugs over their aversive properties likely contributes to the transition from drug use to drug dependence. By inhibiting the activity of DA neurons in the VTA, GABA projections from the rostromedial tegmental nucleus (RMTg) are well suited to shift the balance between drug-induced reward and aversion. Since cannabinoids suppress RMTg inputs to DA cells and CB1 receptors affect alcohol intake in rodents, we hypothesized that the endocannabinoid system, by modulating this pathway, might contribute to alcohol preference. Here we found that RMTg afferents onto VTA DA neurons express CB1 receptors and display a 2-arachidonoylglycerol (2-AG)-dependent form of short-term plasticity, that is, depolarization-induced suppression of inhibition (DSI). Next, we compared rodents with innate opposite alcohol preference, the Sardinian alcohol-preferring (sP) and alcohol-nonpreferring ( $\mathrm{sNP}$ ) rats. We found that DA cells from alcohol-naive sP rats displayed a decreased probability of GABA release and a larger DSI. This difference was due to the rate of 2-AG degradation. In vivo, we found a reduced RMTg-induced inhibition of putative DA neurons in sP rats that negatively correlated with an increased firing. Finally, alcohol failed to enhance RMTg spontaneous activity and to prolong RMTg-induced silencing of putative DA neurons in sP rats. Our results indicate functional modifications of RMTg projections to DA neurons that might impact the reward/aversion balance of alcohol attributes, which may contribute to the innate preference observed in sP rats and to their elevated alcohol intake.

Key words: alcoholism; cannabinoid; dopamine; rostromedial tegmental nucleus; synaptic plasticity; ventral tegmental area

\section{Introduction}

Drug addiction is a psychiatric disease caused by interactions between genetic predisposition and environmental factors. Different theories propose varying mechanisms for this disorder. However, regardless of the theory, a change in activity of midbrain DA neurons appears to be key in the diverse phases of the drug addiction cycle (Piazza and Deroche-Gamonet, 2013). Drug

\footnotetext{
Received May 2, 2014; revised July 8, 2014; accepted Aug. 5, 2014.

Author contributions: M.M., G.C., and M.P. designed research; M.M., C.S., M.D.F., A.C., and C.M. performed research; A.L.M., K.M., G.M., and G.C. contributed unpublished reagents/analytic tools; M.M., C.S., M.D.F., A.C., C.M., S.S., and M.P.C. analyzed data; M.M. and M.P. wrote the paper.

This research was supported by the Italian Ministry of University (Grant PRIN 2009-200928EEX4) and Fondazione Banco di Sardegna (Grant 2012) to M.P. and by National Institutes of Health grants DA011322 and DA021696 to K.M. We thank Dr. Di Marzo for the initial gift of 06340 and S. Aramo for his skillful assistance. Sardegna Ricerche Scientific Park (Pula, CA, Italy) is acknowledged for free access to facilities of the Nanobiotechnology Laboratory.

The authors declare no competing financial interests.

Correspondence should be addressed to Miriam Melis, PhD, University of Cagliari, Department of Biomedical Sciences, Division of Neuroscience and Clinical Pharmacology, Cittadella Universitaria di Monserrato, 09042 Monserrato. E-mail: myriam@unica.it.

DOI:10.1523/JNEUROSCI.1844-14.2014

Copyright $\odot 2014$ the authors $\quad 0270-6474 / 14 / 3412716-09 \$ 15.00 / 0$
}

exposure of midbrain DA neurons switches them from an initial physiological state to a new allostatic state (Koob and Le Moal, 2001). These adaptations constitute the basis for the hedonic homeostatic dysregulation theory (Koob and Le Moal, 2001). Thus, disruption of those brain circuits mediating the balance between reward and aversion are considered as "brain signatures" of clinical states characterizing the different stages of the drug addiction cycle (Koob and Le Moal, 2001; Koob and Volkow, 2010).

GABA neurons of the rostromedial tegmental nucleus (RMTg) regulate activity of DA cells of the VTA (Hong et al., 2011; Lecca et al., 2012). Notably, opioids and cannabinoids decrease firing rate of RMTg GABA neurons, thereby disinhibiting VTA DA cells (Jalabert et al., 2011; Matsui and Williams, 2011; Lecca et al., 2012). However, while RMTg GABA neurons are immunopositive for $\mu$-opioid receptors (Jhou et al., 2009a), only indirect evidence supports the expression of cannabinoid CB1 receptors on these neurons (Lecca et al., 2011, 2012; Melis et al., 2013a). Indeed, upon CB1 receptor activation, RMTg tonic neuronal activity decreases (Lecca et al., 2011), thereby reducing 
GABA release onto VTA DA cells (Lecca et al., 2012) and likely contributing to their excitation (Gessa et al., 1998). Altogether, these observations suggest that the RMTg to VTA GABA pathway might be under physiological retrograde control by endocannabinoids to modulate precisely DA cell activity. Thus, endocannabinoids might ultimately contribute to an enhanced activity of DA cells, involved in the onset of drug addiction, susceptibility to relapse (Marinelli et al., 2003; Melis and Pistis, 2012), and individual vulnerability to drug-seeking behavior (Marinelli and White, 2000; Marinelli et al., 2003; Melis et al., 2009).

An unanswered question in alcohol research is whether differences in selective brain network function (e.g., mesocorticolimbic circuit) represent a biological predisposition toward alcohol abuse, a consequence of it, or both. One strategy to address this is to examine individuals biologically at risk for alcohol abuse, who themselves are not alcohol abusers. We, therefore, took advantage of innate differences in alcohol intake displayed by Sardinian alcohol-preferring ( $\mathrm{sP}$ ) or alcohol-nonpreferring $(\mathrm{sNP})$ rats, which have been selectively bred for their alcohol preference or aversion, respectively (Colombo et al., 2006).

Herein we explored four major aims. (1) Are CB1 receptors expressed onto RMTg terminals impinging on VTA DA cells? (2) Are endocannabinoids retrograde modulators of synaptic strength at this synapse? (3) Is this synapse differently regulated in $\mathrm{sP}$ and sNP rats? (4) Does this synapse show different responsiveness to alcohol in $\mathrm{sP}$ and $\mathrm{sNP}$ rats? To address these issues we used a multidisciplinary approach that involved anatomical, biochemical, and electrophysiological techniques in rodents.

\section{Materials and Methods}

Animals

All procedures were performed in accordance with the Guidelines for the Care and Use of Mammals in Neuroscience and Behavioral Research (National Research Council, 2004 ) and EEC Council Directive (219/ 1990 and 220/1990). We made all efforts to minimize pain and suffering and to reduce the number of animals used. Animals were housed in groups of three to six in standard conditions of temperature $\left(21 \pm 1^{\circ} \mathrm{C}\right)$ and humidity (60\%) under a $12 \mathrm{~h}$ light/dark cycle (lights on at 7:00 A.M.) with food and water available ad libitum. $\mathrm{CB} 1^{-1-}$ mice were obtained, bred, and genotyped as previously described (Marsicano et al., 2002). Alcohol-naive sP and sNP rats were from the 84th generation, and their selective breeding program was previously described (Colombo, 1997).

\section{Immunohistochemistry}

The anterograde tracer dextran-tetramethylrhodamine (Fluoro-Ruby, FR; MW 10,000; $10 \%$ in 0.1 M PBS, pH 7.4; Invitrogen) was bilaterally injected by iontophoresis ( $5 \mu \mathrm{A}, 7 \mathrm{~s}$ on/off cycles for $30 \mathrm{~min}$ ) with glass micropipettes (tip diameter, $10-40 \mu \mathrm{m}$ ) into rat RMTg nucleus (AP, -6.6 to $-7.2 \mathrm{~mm}$ from bregma; $\mathrm{L}, 0.8-1.0 \mathrm{~mm}$ from midline; $\mathrm{V}, 6.5-7.5$ $\mathrm{mm} ; n=6$; Paxinos and Watson, 2007).

Brain tissue preparation. One week following tracer injection, rats were deeply anesthetized with chloral hydrate $(400 \mathrm{mg} / \mathrm{kg}$, i.p.) and transcardially perfused with $4 \%$ paraformaldehyde in $0.1 \mathrm{M}$ PBS, pH 7.4. Coronal sections (40-50 $\mu \mathrm{m}$ thick) of brain were prepared with a cryostat at levels containing the VTA and the RMTg nucleus, and immunostaining was performed on free-floating sections. Adjacent sections were collected and stained with Neutral Red to facilitate the identification of the VTA and the RMTg nucleus. The brains were rapidly removed and postfixed in the same fixative for $3 \mathrm{~h}$. After repeated washing in $0.1 \mathrm{M}$ PBS, brains were cryoprotected in 30\% sucrose in PBS for $48 \mathrm{~h}$.

Immunofluorescent staining. Preblocking of tissue sections was performed with 5\% normal donkey serum (NDS) and 5\% NGS, 1\% BSA, and $0.2 \%$ Triton X-100 in PBS for $1 \mathrm{~h}$ at room temperature. Then, after being washed in $\mathrm{PBS} / 0.2 \%$ Triton $\mathrm{X}-100$, sections were incubated with biotinylated goat anti-rabbit IgG (1:200; Vector Laboratories) and Cy5-labeled donkey anti-mouse IgG (1:300; Jackson ImmunoRe- search) for $1 \mathrm{~h}$ in the dark at room temperature. Subsequently, sections were incubated with Avidin Alexa Fluor 488 for $1 \mathrm{~h}$ in the dark at room temperature, then rinsed and mounted on slides using Vectashield with DAPI dilactate anti-fade, mounting media (Vector Laboratories). Standard control experiments were performed by omission of either the primary or secondary antibody and yielded no cellular labeling.

For double labeling, sections were then incubated for $48 \mathrm{~h}$ at $4^{\circ} \mathrm{C}$ with a mouse monoclonal anti-tyrosine hydroxylase antibody (1:400; Millipore) and with rabbit anti-CB1 receptor polyclonal antibody (1:1000) directed against the last 15 aa of rat CB1 receptor in PBS containing $0.2 \%$ Triton X-100, $0.1 \%$ BSA, $0.5 \%$ NGS, and $0.5 \%$ NDS. Then, sections were incubated with biotinylated goat anti-rabbit IgG (1:200; Vector Laboratories) and Cy5-labeled donkey anti-mouse IgG (1:300; Jackson ImmunoResearch) for $1 \mathrm{~h}$ in the dark at room temperature. Subsequently, sections were incubated with Avidin Alexa Fluor 488 for $1 \mathrm{~h}$ in the dark at room temperature, rinsed, and mounted on slides using Vectashield with DAPI dilactate anti-fade, mounting media (Vector Laboratories). Standard control experiments were performed by omission of either the primary or secondary antibody and yielded no cellular labeling. The specificity of anti-CB1 receptor polyclonal antibody used in this study has been previously demonstrated by showing the lack of immunostaining in CB1 knock-out mice (Ledent et al., 1999; Bodor et al., 2005).

Imaging. All observations were made using an Olympus IX 61 microscope equipped with $2.5,4,10,20$, and $60 \times$ plan apochromatic oilimmersion objectives and images were taken with a 12-bit cooled F View II camera (Olympus). The digital resolution of images taken with the $60 \times$ objective was $0.1 \mathrm{~mm} /$ pixel. Excitation light was attenuated with a $6 \%$ transmittance neutral density filter. After being captured on the computer, images were analyzed using the Cell P AnalySIS1 software module. Color compositions were made using images of single antibodies as RGB channels.

Confocal laser scanning microscopy and image processing. Confocal analysis was performed using a Leica TCS SP5 laser scanning microscope equipped with white light laser super continuum. Images were generated using PL Fluotar $40 \times$ oil (NA 1.25) and $100 \times$ oil (NA 1.4) objectives. Scans were performed in sequence using, separately, channels for fluorescein, rhodamine, and CY5. Resulting datasets were combined, frame by frame, for simultaneous rendering. Maximum intensity, Extended focus, and simulated fluorescence process algorithms (Imaris 7.0) were used. Surface rendering (Imaris 7.0) was used to display and analyze the structures creating shaded solid bodies. Rendered surfaces were interactively displayed and analyzed for global structure properties and interaction between fluorescence.

Quantitative colocalization was performed using dual-color (red and green) confocal images and a specialized software (Imaris 7.6. 1) to calculate the colocalization coefficients. The background was corrected manually using ImageJ software to avoid the bias induced by large noise, background areas in the calculation of the coefficients. The amount of $\mathrm{CB} 1$ receptors localized in RMTg fibers was expressed as the ratio between the volume of colocalized CB1 receptors and the volume of RMTgtraced fibers in the VTA. The degree of overlapping between the two channels (red and green) was evaluated considering the Mander's and Pearson's coefficients in volume datasets.

\section{Autoradiography}

Brain tissue preparation. $\mathrm{sP}$ and $\mathrm{sNP}$ ( $n=6$ rats per rat line) were killed by rapid decapitation, and brains were promptly removed, immediately immersed in isopentane, and then stored at $-80^{\circ} \mathrm{C}$ until sectioning for $\left[{ }^{3} \mathrm{H}\right](-)$-CP55940 autoradiography.

$\left[{ }^{3} \mathrm{H}\right](-)-C P 55940$ binding autoradiography. Coronal sections $12-16$ $\mu \mathrm{m}$ thick were prepared with a cryostat at $-20^{\circ} \mathrm{C}$, thaw mounted onto SuperFrost Plus slides (BDH), and stored with desiccant at $-20^{\circ} \mathrm{C}$ until use. Tissue sections corresponding to plates $37-39$, according to the atlas of Paxinos and Watson (2007), were chosen and adjacent sections to those used for autoradiography were stained with Neutral Red to identify the VTA. $\left[{ }^{3} \mathrm{H}\right](-)$-CP55940 binding autoradiography was performed as previously described (Castelli et al., 2007). Briefly, tissue slides were incubated at $37^{\circ} \mathrm{C}$ for $2.5 \mathrm{~h}$ in $50 \mathrm{~mm}$ Tris- $\mathrm{HCl}, \mathrm{pH} 7.4$, containing 5\% BSA 
and $10 \mathrm{~nm}\left[{ }^{3} \mathrm{H}\right] \mathrm{CP} 55940$ (specific activity, $139.6 \mathrm{Ci} / \mathrm{mmol}$; PerkinElmer). Nonspecific binding was determined in adjacent brain sections in the presence of $10 \mu \mathrm{M}$ unlabeled CP55940. Following incubation, tissue slides were rinsed twice at $4^{\circ} \mathrm{C}$ for $2 \mathrm{~h}$ in ice-cold Tris- $\mathrm{HCl}$ buffer ( $50 \mathrm{~mm}, \mathrm{pH}$ 7.4) with $1 \% \mathrm{BSA}$, once ( $5 \mathrm{~min}$ ) with $50 \mathrm{~mm}$ Tris- $\mathrm{HCl}$, dipped in ice-cold deionized water, and then air dried. Dried tissue sections and slide-mounted $\left[{ }^{3} \mathrm{H}\right]$ microscales standards (RPA 501 and 505; GE Healthcare) were placed in a Fujifilm BAS cassette with a BAS-5000 imaging plate. The resulting images were analyzed with the Fujifilm BAS-5000 imaging system (AIDA; Raytest), and optical densities were transformed into levels of bound radioactivity (femtomoles per milligram of protein) with gray values generated by coexposed $\left[{ }^{3} \mathrm{H}\right]$ standards.

Immunocytochemical detection of tyrosine hydroxylase. After voltage-clamp recordings ex vivo, slices containing biocytin fills were fixed in $4 \%$ paraformaldehyde in $0.1 \mathrm{M}$ PBS, $\mathrm{pH} 7.4$, for $3 \mathrm{~h}$ and washed three times with PBS, $\mathrm{pH}$ 7.4. Preblocking of tissue sections was performed with $10 \%$ NDS, $1 \%$ BSA, and $0.2 \%$ Triton $\mathrm{X}-100$ in PBS for $1 \mathrm{~h}$ at room temperature. Sections were then incubated for $24 \mathrm{~h}$ at $4^{\circ} \mathrm{C}$ with a mouse monoclonal anti-TH antibody (1:400; Millipore) in PBS containing $0.2 \%$ Triton $\mathrm{X}-100,0.1 \% \mathrm{BSA}$, and $1 \% \mathrm{NDS}$. Then, after being washed in PBS $/ 0.2 \%$ Triton X-100, sections were incubated for $2 \mathrm{~h}$ at room temperature with Alexa Fluor 488-labeled donkey anti-mouse IgG (1:500; Invitrogen) and Streptavidin Alexa Fluor 594 (1:1000; Invitrogen) for $2 \mathrm{~h}$ in the dark at room temperature. Sections were then rinsed and mounted on slides using VectaShield antifade mounting media (Vector Laboratories) and visualized using an Olympus IX 61 microscope. Images were taken with a 12-bit, cooled F View II camera (Olympus). Color compositions were made using images of single antibodies as RGB channels. After being captured on the computer, images were analyzed using the Cell P AnalySIS software module.

\section{Electrophysiological studies}

Ex vivo electrophysiology. The preparation of VTA slices was as described previously (Melis et al., 2004b, 2009, Melis et al., 2013b). Briefly, male Sprague Dawley rats (12-30 d; Harlan), sP and sNP rats (12-30 d, from 84th generation), and CBN wild-type and knock-out mice (21-30 d) were anesthetized with isoflurane and killed by guillotine. A block of tissue containing the midbrain was rapidly dissected and sliced in the horizontal plane (300 and $230 \mu \mathrm{m}$ for rat and mouse slices, respectively) with a vibratome (Leica) in ice-cold low- $\mathrm{Ca}^{2+}$ solution containing the following (in mM): $126 \mathrm{NaCl}, 1.6 \mathrm{KCl}, 1.2 \mathrm{NaH}_{2} \mathrm{PO}_{4}, 1.2 \mathrm{MgCl}_{2}, 0.625$ $\mathrm{CaCl}_{2}, 18 \mathrm{NaHCO}_{3}$, and 11 glucose. Slices were transferred to a holding chamber with $\operatorname{ACSF}\left(37^{\circ} \mathrm{C}\right)$ saturated with $95 \% \mathrm{O}_{2}$ and $5 \% \mathrm{CO}_{2}$ containing the following (in $\mathrm{mm}$ ): $126 \mathrm{NaCl}, 1.6 \mathrm{KCl}, 1.2 \mathrm{NaH}_{2} \mathrm{PO}_{4}, 1.2 \mathrm{MgCl}_{2}$, $2.4 \mathrm{CaCl}_{2}, 18 \mathrm{NaHCO}_{3}$, and 11 glucose. Slices were allowed to recover for at least $1 \mathrm{~h}$ before being placed, as hemislices, in the recording chamber and superfused with the ACSF $\left(34-36^{\circ} \mathrm{C}\right)$ saturated with $95 \% \mathrm{O}_{2}$ and $5 \% \mathrm{CO}_{2}$. Cells were visualized with an upright microscope with infrared illumination (Axioskop FS 2 plus; Zeiss), and whole-cell patch-clamp recordings were made by using an Axopatch 200B amplifier (Molecular Devices). Voltage-clamp recordings were made with electrodes filled with a solution containing the following (in $\mathrm{mM}$ ): $144 \mathrm{KCl}, 10 \mathrm{HEPES}$, 3.45 BAPTA, $1 \mathrm{CaCl}_{2}, 2.5 \mathrm{Mg}_{2} \mathrm{ATP}$, and 0.25 $\mathrm{Mg}_{2} \mathrm{GTP}$, pH 7.2-7.4, 275$285 \mathrm{mOsm}$. In addition, random experiments were performed with a K-gluconate internal solution added with biocytin $(0.2 \%)$ to allow for subsequent immunocytochemical detection of TH (Melis et al., 2013b). The K-gluconate internal solution contained the following (in mM): 133.5 K-gluconate, $1.8 \mathrm{NaCl}, 10 \mathrm{HEPES}, 0.05$ EGTA, $1.7 \mathrm{MgCl}_{2}, 2 \mathrm{Mg}_{2} \mathrm{ATP}$, and 0.4 $\mathrm{Mg}_{2} \mathrm{GTP}$, pH 7.2-7.4, 275-285 mOsm. Experiments were begun only after series resistance had stabilized (typically $10-30 \mathrm{M} \Omega$ ). Series and input resistance were monitored continuously on-line with a $5 \mathrm{mV}$ depolarizing step $(25 \mathrm{~ms})$. Data were filtered at $2 \mathrm{kHz}$, digitized at $10 \mathrm{kHz}$, and collected on-line with acquisition software (pClamp 8.2; Molecular Devices). DA neurons from the posterior VTA were identified according to the already published criteria (Melis et al., 2013b): cell morphology and anatomical location (i.e., medial to the medial terminal nucleus of the accessory optic tract), slow pacemaker-like firing rate $(<5 \mathrm{~Hz})$, long action potential duration $(>2 \mathrm{~ms})$, and the presence of a large $I_{h}$ current ( $>100$ pA; Johnson and North, 1992), which was assayed immediately after break-in, using 13 incremental $10 \mathrm{mV}$ hyperpolarizing steps (250 $\mathrm{ms}$ ) from a holding potential of $-70 \mathrm{mV}$. A bipolar, stainless steel stimulating electrode (FHC) was placed $\sim 500 \mu \mathrm{m}$ caudal to the recording electrode and was used to stimulate at a frequency of $0.1 \mathrm{~Hz}$. Paired stimuli were given with an interstimulus interval of $50 \mathrm{~ms}$, and the ratio between the second and the first IPSCs (IPSC2/IPSC1) was calculated and averaged for a 5 min baseline (Melis et al., 2002). The depolarizing pulse used to evoke depolarization-induced suppression of inhibition (DSI; Vincent et al., 1992; Pitler and Alger, 1994) was a $500 \mathrm{~ms}$ to $5 \mathrm{~s}$ step to $+40 \mathrm{mV}$ from holding potential ( $-70 \mathrm{mV}$; (Melis et al., 2004a). This protocol was chosen on the evidence of an endocannabinoid tone when DA cells are held at $+40 \mathrm{mV}$ (Melis et al., 2004a). The magnitude of DSI was measured as a percentage of the mean amplitude of consecutive IPSCs after depolarization (acquired between 5 and $15 \mathrm{~s}$ after the end of the pulse) relative to that of 5 IPSCs before the depolarization.

In vivo electrophysiology. sP and sNP rats (300-380 g) from 84th generation were anesthetized with urethane $(1.3 \mathrm{~g} / \mathrm{kg}$, i.p. $)$, their femoral 
A

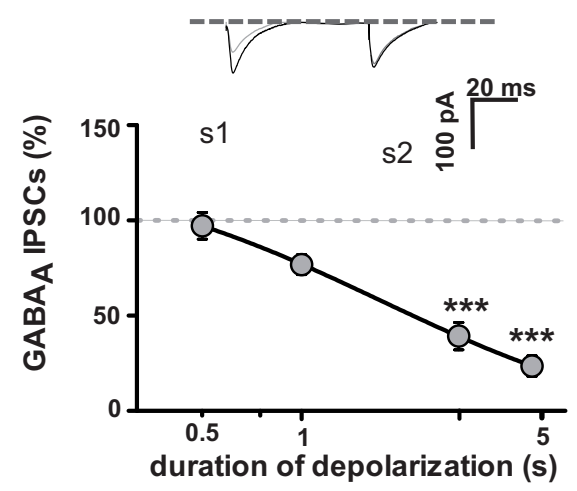

C

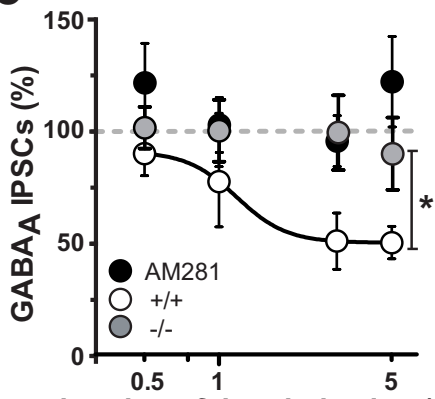

duration of depolarization (s)

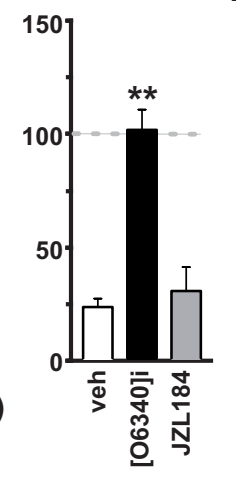

D
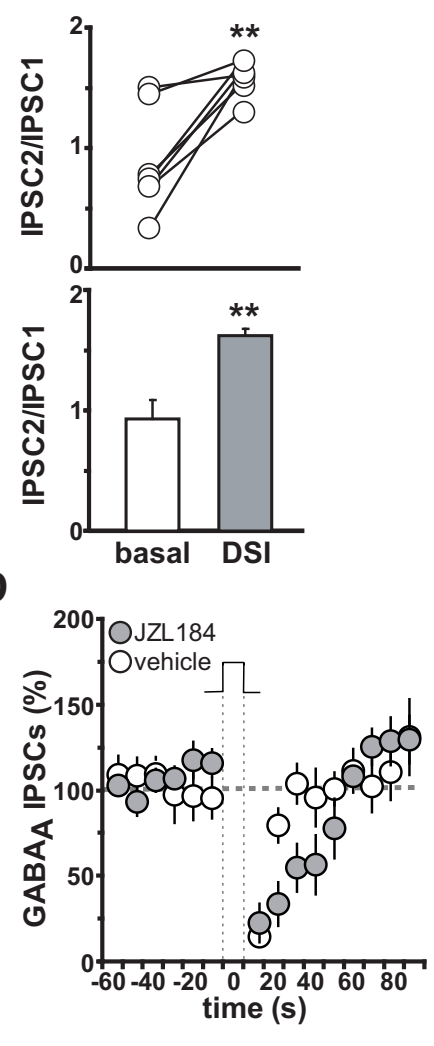

E

biocytin
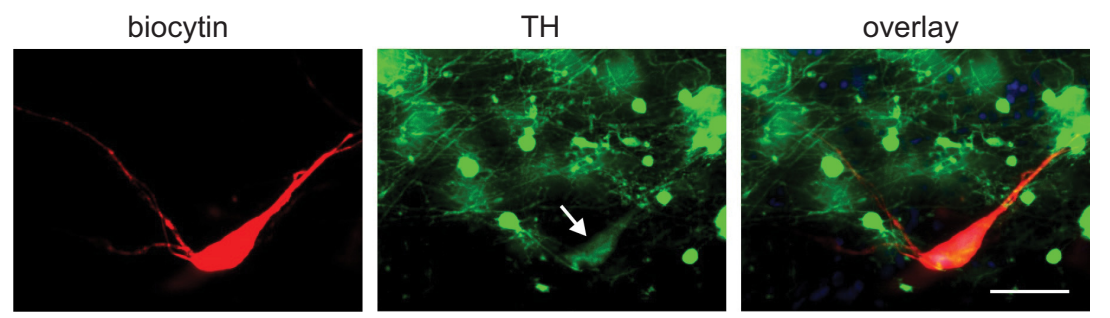

Figure 2. 2-AG activates presynaptic CB1 receptors and mediates DSI in the VTA.A, Application of a depolarizing pulse to VTA DA cells reduces $G A B A_{A} I P S C$ s evoked by stimulating RMTg afferents. The relationship between the depolarizing pulse duration and the

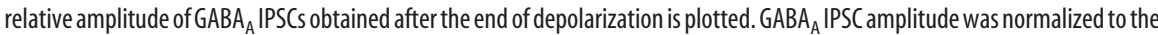
averaged value (dotted line) before depolarization. Each symbol represents the averaged value obtained from seven different cells. Representative traces before and after DSI (5s) are shown in the inset. Gray traces represent the $\mathrm{GABA}_{A} I P S C s$ after the depolarizing step. $B$, DSI increases the paired-pulse ratio (IPSC2/IPSC1). The upper graph plots the paired-pulse ratio for each of the experiments in $\boldsymbol{A}$ before (basal) and $5-15 \mathrm{~s}$ after (DSI) the depolarizing pulse ( $5 \mathrm{~s}$ ), while the lower graph plots the averaged paired-pulse ratio in a bar graph form. C, DSI requires 2-AG, which activates CB1 receptors. The left graph shows that induction of DSI was absent in the presence of either the $\mathrm{CB} 1$ receptor antagonist AM281 (black circles, $n=6$ ) or in $\mathrm{CB}^{-1-}$ mice (gray circles, $n=8$ ). The right graph displays that DSI induction ( 5 s) was also absent in the presence of DAGL inhibitor $(06340, n=8)$, which was applied through the patch pipette, but not by the MAGL inhibitor JZL184 $(n=9)$. D. Time course of DSI in the presence (filled symbols, $n=9$ ) and absence (white symbols, $n=11$ ) of JZL184. Note that JZL184 prolonged DSI decay time. Each symbol represents the averaged value ( \pm SEM) obtained from different recorded cells. Data are expressed as mean $\pm S E M,{ }^{*} p<0.05,{ }^{* *} p<0.01$, and ${ }^{* * *} p<$ 0.0001. $\boldsymbol{E}$, Determination of the DA phenotype using immunohistochemistry. Examples of a rat VTA neuron. Post hoc immunocytochemical detection revealed that example neuron was $\mathrm{TH}(+)$. Neurons that were whole-cell patch clamped were backfilled by including biocytin in the recording pipette (red). TH immunohistochemistry routinely labeled the TH-positive neurons (green). Scale bar, $20 \mu \mathrm{m}$.

vein was cannulated for intravenous administration of alcohol, and placed in the stereotaxic apparatus (Kopf) with their body temperature maintained at $37 \pm 1^{\circ} \mathrm{C}$ by a heating pad. Thereafter, the scalp was retracted and one burr hole was drilled above the VTA $(\mathrm{AP},+2.0 \mathrm{~mm}$ from the tip of the lambda; $\mathrm{L}, 0.4-0.6 \mathrm{~mm}$ from midline; $\mathrm{V}, 7.0-8.0$ $\mathrm{mm}$ ) for the placement of a recording electrode. Extracellular single-unit activity of putative DA neurons located in the VTA was recorded according to the already published criteria (Lecca et al., 2012) and references therein). VTA putative DA neurons were selected when all criteria for identification were fulfilled: firing rate $<10 \mathrm{~Hz}$ and duration of action potential $>2.5 \mathrm{~ms}$ as measured from start to end. Bursts were defined as the occurrence of two spikes at interspike interval $<80$ $\mathrm{ms}$, and terminated when the interspike interval exceeded $160 \mathrm{~ms}$ (Grace and Bunney, 1983). Isolated putative DA neurons were filtered (bandpass $0.1-10.000 \mathrm{~Hz}$ ) and recorded for 2 min to establish basal firing properties. $\mathrm{RMTg}$ (AP, from -6.8 to $-7.2 \mathrm{~mm}$ from bregma; L, 0.7-0.9 mm from midline; $\mathrm{V}, 6.5-7.5$ $\mathrm{mm}$ ) single-unit activity of putative GABA cells was recorded extracellularly according to previously described criteria (Jhou et al., 2009b; Lecca et al., 2011). RMTg GABAcontaining neurons displayed a relatively high spontaneous firing rate $(>10 \mathrm{~Hz})$ and a biphasic and short $(<1.5 \mathrm{~ms})$ action potential. Single-unit activity was filtered (bandpass, 0.3 $3.000 \mathrm{~Hz}$ ), individual spikes were isolated by means of a window discriminator (Digitimer), and displayed on a digital storage oscilloscope (TDS 3012; Tektronics). Experiments were sampled on-line and off-line with Spike2 software (Cambridge Electronic Design) by a computer connected to CED 1401 interface (Cambridge Electronic Design).

To evaluate the inhibitory input arising from the RMTg to the VTA, a Formvar-coated, stimulating stainless steel bipolar electrode ( $250 \mu \mathrm{m}$ tip diameter) was aimed at the ipsilateral RMTg (AP, -7.2 mm from bregma; L, 0.8 $\mathrm{mm}$ from midline; $\mathrm{V} 6.5 \mathrm{~mm}$ from cortical surface) according to the stereotaxic atlas of Paxinos and Watson (2007). The electrode was inserted with an inclination of $20^{\circ}$ anteroposterior on the coronal plane $(\mathrm{V}, 7 \mathrm{~mm}$ from cortical surface). The stimulation protocol was as described previously (Lecca et al., 2011): once a cell was selected, electrical stimuli consisting of single, monophasic rectangular pulses $(0.5$ $\mathrm{mA}, 0.3-0.5 \mathrm{~ms}$ ) were delivered to the RMTg at $1 \mathrm{~Hz}$. Responses to electrical stimulation of the RMTg were evaluated, and a peristimulus time histogram (PSTH) was generated on-line for each neuron. A cell was considered inhibited or excited when the number of action potentials per bin (bin length $=1 \mathrm{~ms}$ ) in the $50 \mathrm{~ms}$ after the stimulus was significantly lower or higher (one-way ANOVA for repeated measures), respectively, than baseline levels (the number of action potentials per bin in the $50 \mathrm{~ms}$ period before the stimulus). The duration of stimulusevoked inhibition was defined as the time of complete cessation of firing after the stimulus (Lecca et al., 2012).

In a separate set of experiments, alcohol $(20 \% \mathrm{w} / \mathrm{v}$ in saline $)$ was administered intravenously in a cumulative dose regimen (1.2-5.0 $\mathrm{ml} / \mathrm{kg}$ body weight). Changes in firing rate and duration of inhibition were calculated by averaging the effects of alcohol for the 2 min period following drug administration and comparing them to the mean of predrug baseline. When alcohol was administered, only one cell was recorded per rat.

At the end of the recording sessions, DC current ( $15 \mathrm{~mA}$ for $5 \mathrm{~min}$ ) was passed through the recording micropipette to eject Pontamine sky blue for marking the recording site. Brains were then rapidly removed and 
fixed in $4 \%$ paraformaldehyde solution. The position of the electrodes was microscopically identified on serial sections $(60 \mu \mathrm{m})$ stained with Neutral Red.

\section{Statistical analysis}

All the numerical data are given as mean \pm SEM. Data were analyzed by using two-way ANOVA for repeated measures (treatment $X$ time), or one-way ANOVA or Student's $t$ test for repeated measures, when appropriate. Post hoc multiple comparisons were made using either the Dunnett's test or Bonferroni's test. The significance level was established at $p<0.05$.

\section{Results}

\section{$\mathrm{CB} 1$ receptor localization on $\mathrm{RMTg}$} GABA afferents onto VTA DA neurons of Sprague Dawley rats

As shown in Figure 1, FR injections into the RMTg resulted in anterogradely labeled axons within the VTA, which confirmed that the RMTg projects to the VTA (Jhou et al., 2009a). Next, to investigate whether RMTg neurons projecting to the VTA contain CB1 receptors, we combined FR tract-tracing and immunolabeling techniques using highly specific anti-CB1 receptor polyclonal antibody with confocal laser scanning microscope analysis in the VTA. CB1 immunoreactivity was colocalized within anterogradely labeled axons in the VTA (Fig. 1 C,D).

CB1-immunopositive puncta were detected in $40.8 \pm 0.9 \%$ of RMTg fibers within the VTA in standard confocal volume, whereas colocalization analysis (Figure $1 C$ ) showed that the average volume of colocalized CB1 immunofluorescence in traced fibers was $0.046 \pm 0.004 \mu \mathrm{m}^{3}$ (Mander's coefficient $=0.04685$ ) equal to the $4.6 \%$ of fiber volume. Pearson's coefficient value for linear correlation, as a measure of pixel overlapping, was 0.554 on average, showing a positive linear relationship between the variables. 3D rendering, reconstruction, and vectorialization algorithms were used to better understand the relationship among anatomical elements studied (Figure 1D).

\section{Functional role of $\mathrm{CB} 1$ receptor} activation on RMTg GABA cells projecting to Sprague Dawley rat VTA DA neurons ex vivo

To investigate the functional role of CB1 receptor activation by endogenous cannabinoids and to examine endocannabinoid nature and integrity at this synapse, we used the commonly applied electrophysiological protocol of DSI (Diana and Marty, 2004). We recorded IPSCs, in a whole-cell configuration, from lateral posterior VTA DA neurons. Although we
A



C

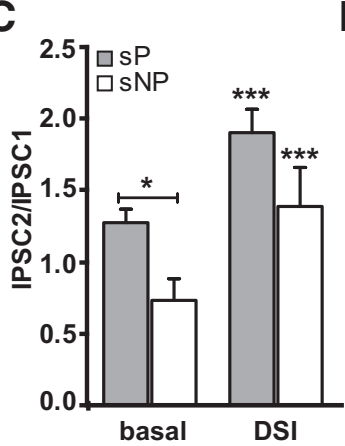

D
B

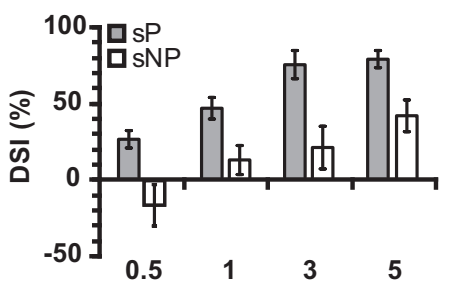

duration of depolarization (s)

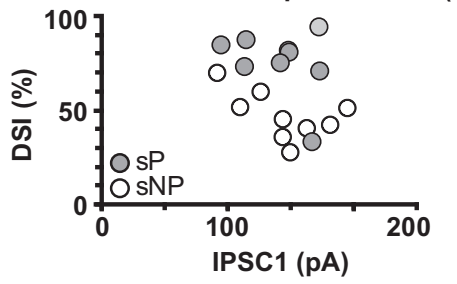

E
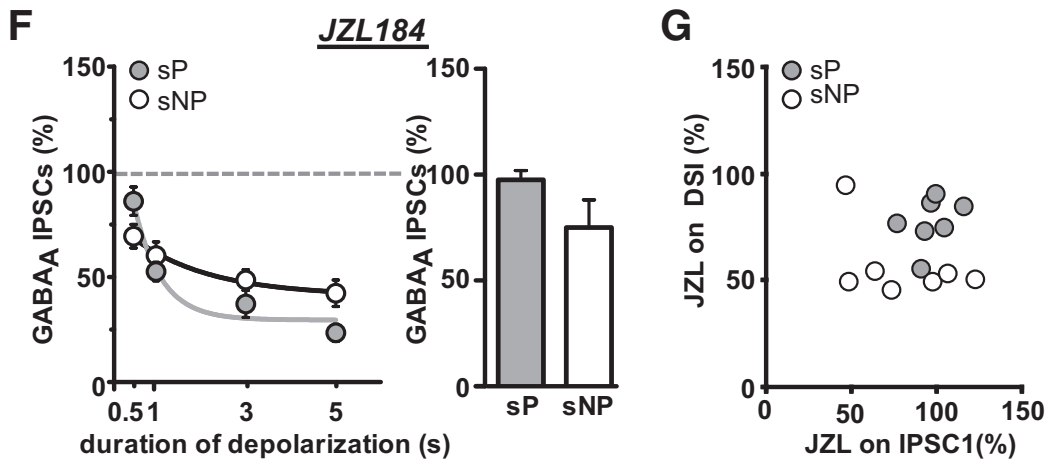

Figure 3. Endocannabinoid modulation of inhibitory transmission arising from caudal afferents is larger in alcohol-naive $S P$ rats. $A$, Application of a depolarizing pulse on VTA DA cells induced a larger reduction of $G_{A B A} I P S C s$ evoked by stimulating RMTg afferents in alcohol-naive $S P$ rats. The relationship between the depolarizing pulse duration and the relative amplitude of $G A B A_{A}$

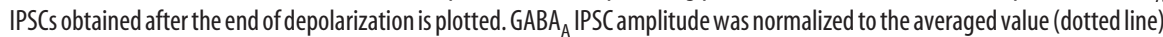
before depolarization. Each symbol represents the averaged value obtained from different cells ( $n=9$ for both rat lines). Representative traces before and after DSI $(5 \mathrm{~s})$ are shown in the inset. Gray traces represent the GABA $\mathrm{APSC}$ s after the depolarizing step. $\boldsymbol{B}$, Averaged data for DSI induced by depolarizing pulses with a duration of $0.5,1,3$, and $5 \mathrm{~s}$ are plotted (top). No correlation was found between DSI magnitude and size of GABA IPSC in alcohol-naive SP and sNP rats (bottom). $C$, Bar graph summarizing the

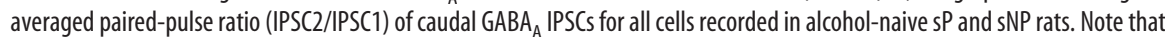
VTA DA cells recorded from alcohol-naive SP rats display a paired-pulse facilitation. No difference between $S P$ and $S N P$ rats was found in the magnitude of DSI-induced increased paired-pulsed ratio. $\boldsymbol{D}$, Dose-response curves for percentage inhibition in amplitude of $\mathrm{GABA}_{A}$ IPSCS by the CB1 receptor agonist WIN55,212-2 as recorded from VTA DA cells and evoked by stimulating caudal afferents. Each symbol represents the averaged value ( \pm SEM) obtained from different cells ( $n=4-5$ for both rat lines). $\boldsymbol{E}$, Specific binding of the $\mathrm{CB} 1$ receptor agonist $\left[{ }^{3} \mathrm{H}\right] \mathrm{CP} 55940$ was similar in the VTA of alcohol-naive sP $(n=6)$ and $\mathrm{NP}(n=6)$ rats. $F$, MAGL inactivation induced similar DSI in alcohol-naive sP and SNP rats ( $n=7$ for both rat lines). The relationship between the depolarizing pulse duration and the relative amplitude of $G A B A_{A} I P S C s$ obtained after the end of depolarization in the presence of MAGL inhibitor JZL184 in SP and SNP rats is plotted. GABA IPSC amplitude was normalized to the averaged value (dotted line) before depolarization. Each symbol represents the averaged value obtained from different cells (left). Bar graph showing the effect of JZL184 (100 nm, $5 \mathrm{~min}$ ) on GABA $A$ IPSC amplitude in alcohol-naive sP and sNP rats. G, No correlation was found between DSI magnitude and size of first GABA $A_{A}$ IPSC (IPSC1) in either SP or SNP JZL184-treated rats. Data are expressed as mean \pm SEM, ${ }^{*} p<0.05$, and ${ }^{* * *} p<0.0001$. 
A

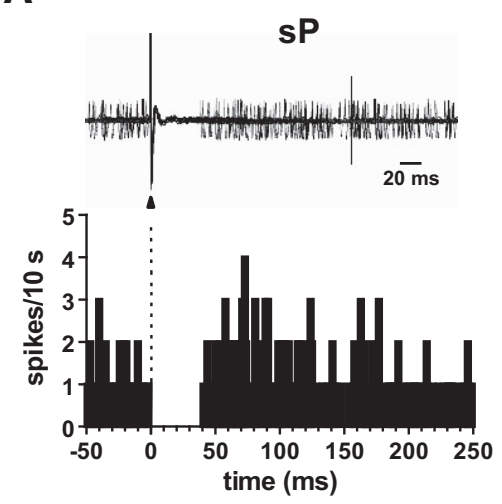

B

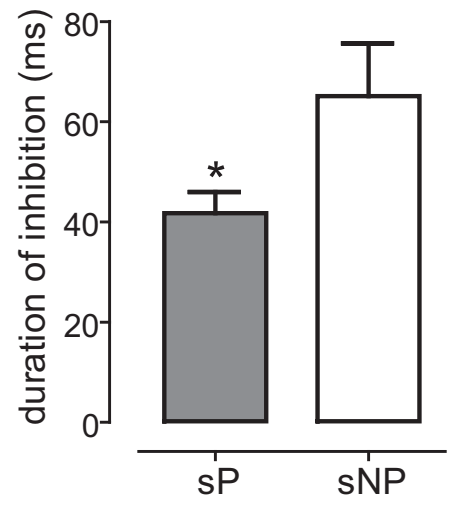

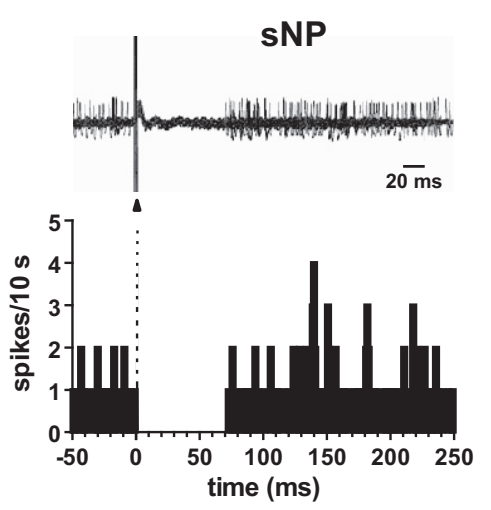

C

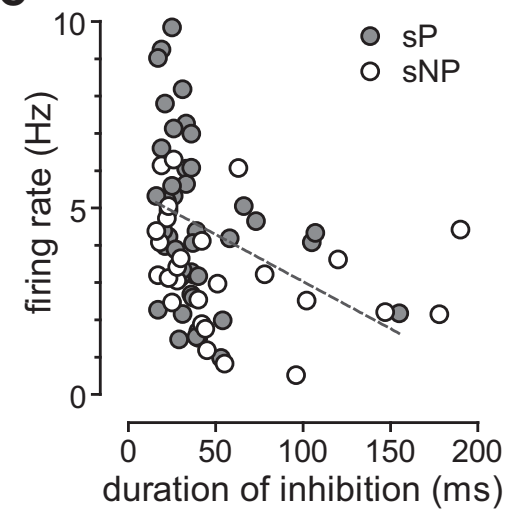

Figure 4. Inhibition mediated by RMTg GABA cells projecting to VTA DA neurons in sP rats is shorter than sNP rats in vivo. $\boldsymbol{A}$, Traces acquired from a digital oscilloscope (top) and PSTH of the same cell (bottom), showing that RMTg stimulation induces a complete inhibition of discharge activity of a VTA DA neuron for $\sim 40 \mathrm{~ms}$ in sP rats (left) and for $\sim 70 \mathrm{~ms}$ in sNP rats (right). $B$, Graph histogram showing mean inhibitory response to RMTg stimulation onto VTA DA cells from sP $(n=40)$ and sNP $(n=23)$ rats. The duration of RMTg-evoked inhibition in sP rats was significantly shorter, when compared with sNP rats. C, The duration of RMTg-evoked inhibition is negatively correlated with the spontaneous discharge activity of VTA DA neurons in $\mathrm{SP}$ rats; $r^{2}=0.09,{ }^{*} p<0.05$.

cannot identify definitively the sources of inhibitory afferents, we can assume that most of the caudal inputs electrically stimulated in our preparation are presumably originating from the RMTg (Matsui and Williams, 2011), given that it is one of the main caudally located inhibitory sources to the VTA. When we applied $0.5,1,3$, and $5 \mathrm{~s}$ depolarization, we found that VTA DA cells expressed DSI at these synapses $(n=7$ cells from four rats; oneway ANOVA, $F_{(3,18)}=0.31, p<0.0001$; Fig. $2 A$ ). DSI was accompanied by an increased paired-pulse ratio (paired $t$ test, $p<0.01$; Fig. $2 B$ ) suggestive of a presynaptic locus of action. DSI required activation of $\mathrm{CB} 1$ receptors, since it was blocked in the presence of the CB1 receptor antagonist AM281 $(0.5 \mu \mathrm{M} ; n=6$ cells from four rats; two-way ANOVA, $F_{(1,33)}=26.8, p<0.001$; Fig. $\left.2 C\right)$, and absent in $\mathrm{CB} 1^{-1-}$ mice $(n=7$ cells from five wild-type mice and $n=8$ from four knock-out mice; two-way ANOVA, $F_{(1,36)}=$ 7.76, $p<0.05$; Fig. 2C).

Among the endocannabinoids, 2-AG has been found to play a key role in shaping synaptic plasticity in the VTA (Melis and Pistis, 2012). Therefore, to identify the molecular nature of the endocannabinoid responsible for DSI, we first took advantage of specific inhibitors of the key enzymes synthesizing and degrading 2-AG, diacylglycerol lipase (DAGL) and monoacylglycerol lipase (MAGL; Blankman et al., 2007), respectively. In the presence of DAGL inhibitor O6340 (5 $\mu \mathrm{M}$ applied through the patch pipette) DSI was absent ( $n=8$ cells from five rats; two-way ANOVA,
$F_{(1,45)}=11.41, p<0.01$; Fig. $\left.2 C\right)$. However, when midbrain slices were perfused with the MAGL inhibitor JZL184 (100 nM; Long et al., 2009), we found that the magnitude of DSI was similar to vehicletreated slices (two-way ANOVA, $F_{(1,42)}=$ $0.94, p>0.05$; Fig. $2 C, D)$, although DSI decay time was prolonged $(n=9$ cells from six rats; two-way ANOVA followed by Bonferroni post hoc test, $F_{(14,252)}=$ 1.87, $p<0.05$; Fig. 2D).

To determine whether the neurons were indeed DA neurons, we randomly filled them with biocytin while recording $\mathrm{GABA}_{\mathrm{A}}$-IPSCs and targeting the same neuronal population. Subsequently the slices were processed for TH (Fig. 2E). Thus, 2-AG accounts for DSI at these afferents onto VTA DA cells, and its signal can be pharmacologically manipulated.

\section{Difference in DSI at RMTg inhibitory synapses onto VTA DA cells between $\mathrm{sP}$ and $s$ NP rats ex vivo}

Converging evidence suggests that innate differences in the endocannabinoid system might be associated with opposite alcohol preference displayed by sP and sNP rats (Colombo et al., 2005, 2006; Melis et al., 2009; Vinod et al., 2012). Particularly, we previously described a decreased probability of GABA release (i.e., a paired-pulse facilitation of GABA IPSCs accompanied by a decreased mIPSC frequency, with no change in amplitude, in sP vs sNP rats) at rostral afferents of sP rats when compared with sNP rats (Melis et al., 2009). In addition, DSI at rostral afferents significantly differed in $\mathrm{sP}$ versus $\mathrm{sNP}$ rats, being larger in $\mathrm{sNP}$ than $\mathrm{sP}$ rats (Melis et al., 2009). Therefore, to investigate whether or not endocannabinoid system function and integrity at inhibitory synapses presumably arising from the RMTg differed between the two rat lines, we compared DSI in sP and sNP rat VTA DA neurons. As shown in Figure 3, $A$ and $B$, DSI was larger in sP rats when compared with sNP rats $(n=9$ cells from four and five rats for sNP and sP rats, respectively; two-way ANOVA, $F_{(1,48)}=29.5$, $p<0.0001)$. Importantly, the different magnitudes of DSI did

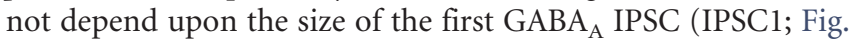
$3 B$ ), being similar between $\mathrm{SP}$ and $\mathrm{sNP}$ rats. DSI was accompanied by an increased paired-pulse ratio (two-way ANOVA, $F_{(1,15)}=40.7$, $p<0.0001$; Fig. 3C) suggestive of a presynaptic locus of action. Notably, we also observed that the initial probability of GABA release was different between $\mathrm{sP}$ and $\mathrm{sNP}$ rats. In fact, $\mathrm{sP}$ rat VTA DA cells expressed a paired-pulse facilitation (two-way ANOVA, $F_{(1,15)}=5.3, p<0.05$; Fig. $\left.3 C\right)$, which is consistent with the previously reported decreased mIPSC frequency observed in $\mathrm{sP}$ rats (Melis et al., 2009). Hence, sP and sNP rat VTA DA cells displayed a paired-pulse facilitation and depression, respectively.

The larger DSI expressed by VTA DA cells in sP rats might reflect either higher levels of 2-AG and/or an increased number or activity of $\mathrm{CB} 1$ receptors. To assess whether differences in $\mathrm{CB} 1$ receptor activity/number occur at GABA synapses arising from caudal afferents onto VTA DA neurons of sP and sNP rats, the 
CB1 receptor agonist WIN55,212-2 (WIN) was bath applied. WIN (0.01-3 $\mu \mathrm{M}, 5 \mathrm{~min})$ similarly reduced caudal $\mathrm{GABA}_{\mathrm{A}}$ IPSCs in $\mathrm{sP}$ and $\mathrm{sNP}$ rats $(n=4-5$ cells from four rats from both groups; two-way ANOVA, $F_{(1,32)}=0.01, p>0.05$; Fig. $3 D$ ). Accordingly, when autoradiography was performed in the VTA, basal $\left[{ }^{3} \mathrm{H}\right] \mathrm{CP} 55940$ binding was found to be similar in $\mathrm{sP}$ and $\mathrm{sNP}$ rats (unpaired $t$ test, $n=6, p>0.05$; Fig. 3E). These results suggest that differences in $\mathrm{CB} 1$ receptors cannot account for the dichotomy in DSI between $\mathrm{sP}$ and sNP rats.

Degradation of 2-AG by MAGL is often the rate-limiting step that determines the time course of DSI in the brain (Pan et al., 2009) including at these synapses (Melis et al., 2013a). We therefore examined the effects of JZL184 on DSI in both rat lines. In the presence of JZL184 (100 nM, 5 min pre-incubation), which per se was ineffective (Fig. 3F; unpaired $t$ test, $p>$ $0.05)$, DSI no longer differed between $\mathrm{sP}$ and sNP rats $(n=7$ cells from four rats in both groups; two-way ANOVA, $F_{(1,36)}=$ $0.9, p>0.05$; Fig. $3 F$ ). Importantly, the JZL184-induced effect on DSI magnitude did not depend on the size of the first GABA $_{\mathrm{A}}$ IPSC (IPSC1; Fig. $3 G$ ), being similar between $\mathrm{sP}$ and $\mathrm{sNP}$ rats.

\section{Inhibition from RMTg GABA cells} projecting to VTA DA neurons of sP rats differs from sNP rats in vivo

We previously reported that VTA DA neuron discharge rate of sP rats in vivo is higher than sNP rats (Melis et al., 2009), and that in Sprague Dawley rats firing activity of VTA DA cells negatively correlates with duration of inhibition induced by stimulating the RMTg (Lecca et al., 2012). We, therefore, further characterized the inhibitory contribution from RMTg afferents to VTA putative DA neurons in $\mathrm{sP}$ and $\mathrm{NNP}$ rats in vivo. To accomplish this aim, a sampling of posterior VTA putative DA neurons was performed in $\mathrm{SP}(n=12)$ and $\mathrm{sNP}(n=9)$ rats while stimulating the RMTg. The duration of inhibition evoked by RMTg stimulation was shorter in $\mathrm{sP}$ than $\mathrm{sNP}$ rats (unpaired $t$ test, $p<0.05$; Fig. $4 A, B)$. Additionally, we found a negative correlation between the duration of inhibition and spontaneous firing rate in $\mathrm{sP}$ rats $\left(F_{(1,42)}=4.17 ; r^{2}=0.09, p<0.05\right.$, Pearson's test; Fig. $\left.4 C\right)$. The averaged spontaneous firing rate of VTA putative DA cells of sP and sNP rats was different, being $4.7 \pm 0.2(n=107)$ and $3.5 \pm$ $0.2 \mathrm{~Hz}(n=83)$, respectively (unpaired $t$ test, $p<0.0001)$. In contrast, no difference in standard basal electrophysiological parameters was found when RMTg neuronal firing rates were compared between $\mathrm{sP}$ and $\mathrm{NNP}$ rats, with a discharge frequency of $14.3 \pm 0.7(n=53)$ and $14.7 \pm 0.8(n=55) \mathrm{Hz}$ for sP and sNP rats, respectively (unpaired $t$ test, $p>0.05$ ).

Given that sP and sNP rats show opposite alcohol preference, we next examined alcohol effects on RMTg GABA cell-firing rate. Alcohol (from 0.25 up to $2 \mathrm{~g} / \mathrm{kg}$, i.v.) produced a dose-dependent increase in the firing rate of RMTg GABA neurons in sNP rats (one-way ANOVA for repeated measures, $F_{(4,16)}=4.35, p<$ 0.01 ; Fig. $5 A, B$ ), whereas its effect was absent in sP rats (one-way
B
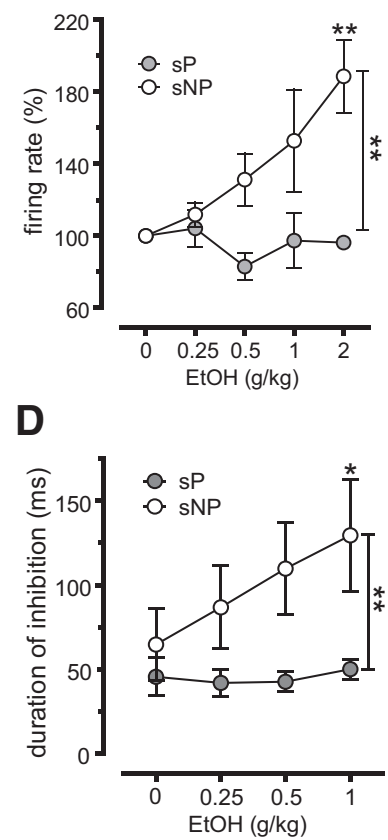

Figure 5. Distinct effects of alcohol administration between sP and sNP rats in vivo. $\boldsymbol{A}$, Representative firing rate histograms of S ibition is increased in VTA DA neurons by alcohol in SNP (right) but not in SP rats (left). $D$, Graph showing that alcohol dose expressed as mean \pm SEM; ${ }^{*} p<0.05,{ }^{* *} p<0.01$.
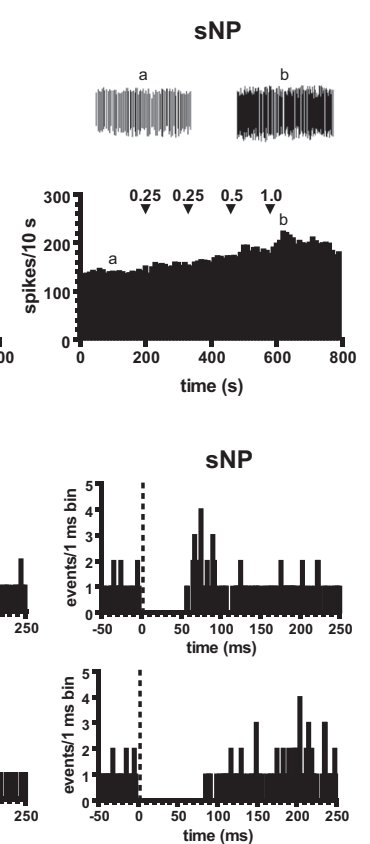

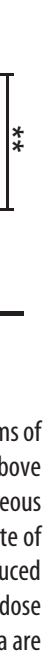

ANOVA for repeated measures, $F_{(4,28)}=2.78, p>0.05$; Fig. $5 A, B)$, thus unveiling another difference between the two rat lines (two-way ANOVA, $F_{(1,44)}=11.33, p<0.01$ ). Together, these results suggest that while basal spontaneous activity of RMTg GABA cells does not differ between the rat lines, their response to alcohol is dramatically different. We next examined whether or not this is reflected in VTA activity by stimulating the RMTg and recording VTA putative DA cells. Accordingly, alcohol $(0.25-1 \mathrm{~g} / \mathrm{kg}$, i.v. $)$ dose dependently increased the duration of inhibition evoked by RMTg stimulation in $\mathrm{sNP}$ but not $\mathrm{sP}$ rats (two-way ANOVA, $F_{(1,27)}=6.49, p<0.05$; Fig. $5 C, D$ ).

\section{Discussion}

Pinpointing neurobiological difference(s) between individuals biologically at risk, and those not at risk, for alcohol dependence, who are not yet themselves alcohol dependent, may provide effective strategies to prevent alcohol abuse. In this current study, we took advantage of innate opposite differences in alcohol preference and consumption displayed by sP or sNP rats. These selectively bred lines provide a model of how genetic factors may contribute to distinct vulnerability to some behavioral actions of alcohol. We found that basal synaptic function of an endocannabinoid-mediated synaptic plasticity from RMTg GABA terminals onto VTA DA cells differed between these rat lines. Specifically, sP rats displayed a reduced probability of GABA release from RMTg terminals onto DA neurons ex vivo, which was paralleled by a reduced RMTg-induced suppression of VTA putative DA neuronal activity in vivo. Notably, in sP rats the increased spontaneous activity of VTA putative DA neurons negatively correlated with the duration of inhibition evoked by 
RMTg stimulation, while spontaneous activity of RMTg cells was similar between sP and sNP rats. This is in agreement with other reports showing that RMTg GABA neurons powerfully control VTA DA neuronal activity (Jhou et al., 2009b; Lecca et al., 2012). It is worth mentioning that we cannot identify definitively the sources of inhibitory afferents in the slice preparation. However, because the RMTg is a major caudal input to the VTA, and because our previous investigation (Lecca et al., 2012) is consistent with another study where the effects of electrical stimulation were compared with optogenetic stimulation of fibers arising from RMTg (Matsui and Williams, 2011), we can assume that the afferents electrically stimulated in our slice preparation might be arising from the RMTg.

Remarkably, alcohol administration to sP rats did not affect RMTg GABA cell spontaneous activity in vivo, whereas alcohol enhanced RMTg GABA neuronal activity in sNP rats. Accordingly, RMTg-induced silencing of VTA putative DA cells was not altered by alcohol administration in $\mathrm{sP}$ rats, while alcohol prolonged it in sNP rats. This is consistent with the notion that the RMTg serves as a relay for signaling aversive events to VTA DA cells (Bromberg-Martin et al., 2010). Indeed, genetic factors have been shown to be important in determining whether or not alcohol will be perceived as aversive or rewarding in rodents (Rezvani et al., 2010). This is also in agreement with the notion that the motivational effects of alcohol are critical in modulating drug seeking and taking in both laboratory animals and humans (Cunningham et al., 2000).

While the mechanisms underlying such differences remain to be fully identified, the neuroadaptations occurring at RMTg GABA synapses onto VTA DA cells of sP rats might contribute to the increased spontaneous activity of DA cells. Indeed, in sP rats the paired-pulse modulation of $\mathrm{GABA}_{\mathrm{A}}$ IPSCs showed a facilitation (present results) that together with the decreased frequency of mIPSCs (Melis et al., 2009) are indicative of a decreased probability of GABA release. On the other hand, sNP rat VTA DA neurons displayed a paired-pulse depression at these synapses, thus suggesting that RMTg GABA afferents might be hyperactive, and help explaining the longer duration of inhibition from RMTg GABA cells as well as their genetically based aversion to alcohol (Brunetti et al., 2002).

VTA DA cells recorded from sP rats also expressed a larger DSI at these synapses when compared with sNP rats. A possible explanation for the observed larger DSI in sP rats would have been a larger number of presynaptic $\mathrm{CB} 1$ receptors, or a greater effect produced by their activation. This was not the case as our results indicate that $\mathrm{CB} 1$ receptor expression and function is not different between sP and sNP rats. Remarkably, the observation that 2-AG signal is enhanced in either time and/or space at these inhibitory afferents impinging upon VTA DA neurons in sP rats is consistent with studies reporting that both short- and longterm exposure to alcohol increases endocannabinoid levels in many brain regions (Basavarajappa et al., 2000; Vinod et al., 2006; Rubio et al., 2007) including the midbrain (González et al., 2004). Similar to other reports (Pan et al., 2009; Yoshida et al., 2011), 2-AG degradation by MAGL determined the strength of retrograde synaptic depression. Particularly, pharmacological blockade of MAGL resulted in a similar DSI expressed by sNP and sP rat DA cells. Whether or not this can be ascribed to innate disparity in sensitivity/activity of the MAGL in sP and sNP rats remains to be elucidated.

Finally, our study helps to elucidate several mechanisms participating in homeostatic regulation of VTA DA neuronal activity (Ikemoto and Bonci, 2014), establishing endocannabinoids as key players in fine-tuning DA output (Melis and Pistis, 2012). Indeed, our anatomical and physiological data indicate the presence of CB1 receptors on a large proportion $(\sim 40 \%)$ of $\mathrm{RMTg}$ GABA afferents onto DA cells of the posterolateral VTA. Particularly, confocal analysis indicated the localization of CB1 receptors in close contact with VTA DA neurons. Our ex vivo physiological results provide a functional role for $\mathrm{CB} 1$ receptors at these synapses with DSI absent when CB1 receptors were either pharmacologically blocked or genetically deleted. Additionally, ex vivo observations demonstrated a functional role of $2-A G$ as the mediator of this DSI in the VTA, since DSI was prevented when DA cells were loaded with a DAGL inhibitor, and prolonged when 2-AG degradation was slowed by MAGL inhibition. This molecular convergence of 2-AG signaling at RMTg $\rightarrow$ VTA synapses might make $\mathrm{SP}$ rats less sensitive to the aversive properties of alcohol, which are known to be crucial in the acquisition of alcohol-taking behavior (Stolerman, 1992). Hence, 2-AG actions via $\mathrm{CB} 1$ receptors at caudal synapses (i.e., RMTg $\rightarrow$ VTA) might decrease aversive signal encoded by RMTg GABA cells, and increase the net rewarding/salient yield encoded by VTA DA neurons in $\mathrm{sP}$ rats, while decreasing it in sNP rats.

In conclusion, our results provide evidence that a genetic predisposition for enhanced alcohol preference is accompanied by an increased spontaneous activity of putative DA neurons, a reduced GABA input from RMTg to VTA putative DA cells, and changes in endocannabinoid-mediated transmission at these synapses.

\section{References}

Basavarajappa BS, Saito M, Cooper TB, Hungund BL (2000) Stimulation of cannabinoid receptor agonist 2-arachidonylglycerol by chronic ethanol and its modulation by specific neuromodulators in cerebellar granule neurons. Biochim Biophys Acta 1535:78-86. CrossRef Medline

Blankman JL, Simon GM, Cravatt BF (2007) A comprehensive profile of brain enzymes that hydrolyze the endocannabinoid 2-arachidonoylglycerol. Chem Biol 14:1347-1356. CrossRef Medline

Bodor AL, Katona I, Nyíri G, Mackie K, Ledent C, Hájos N, Freund TF (2005) Endocannabinoid signaling in rat somatosensory cortex: laminar differences and involvement of specific interneuron types. J Neurosci 25:6845-6856. CrossRef Medline

Bromberg-Martin ES, Matsumoto M, Hikosaka O (2010) Dopamine in motivational control: rewarding, aversive, and alerting. Neuron 68:815-834. CrossRef Medline

Brunetti G, Carai MA, Lobina C, Melis S, Serra S, Vacca G, Gessa GL, Colombo G (2002) Differences in ethanol-induced conditioned taste aversion in Sardinian alcohol-preferring and Sardinian alcohol-nonpreferring rats. Alcohol 26: 167-172. CrossRef Medline

Castelli MP, Piras AP, Melis T, Succu S, Sanna F, Melis MR, Collu S, Ennas MG, Diaz G, Mackie K, Argiolas A (2007) Cannabinoid CB1 receptors in the paraventricular nucleus and central control of penile erection: immunocytochemistry, autoradiography and behavioral studies. Neuroscience 147:197-206. CrossRef Medline

Colombo G (1997) ESBRA-Nordmann, 1996 Award Lecture: ethanol drinking behaviour in Sardinian alcohol-preferring rats. Alcohol Alcohol 32:443-453. CrossRef Medline

Colombo G, Serra S, Vacca G, Carai MA, Gessa GL (2005) Endocannabinoid system and alcohol addiction: pharmacological studies. Pharmacol Biochem Behav 81:369-380. CrossRef Medline

Colombo G, Lobina C, Carai MA, Gessa GL (2006) Phenotypic characterization of genetically selected Sardinian alcohol-preferring ( $\mathrm{sP}$ ) and -nonpreferring (sNP) rats. Addict Biol 11:324-338. CrossRef Medline

Cunningham CL, Fidler TL, Hill KG (2000) Animal models of alcohol's motivational effects. Alcohol Res Health 24:85-92. Medline

Diana MA, Marty A (2004) Endocannabinoid-mediated short-term synaptic plasticity: depolarization-induced suppression of inhibition (DSI) and depolarization-induced suppression of excitation (DSE). Br J Pharmacol 142:9-19. CrossRef Medline

Gessa GL, Melis M, Muntoni AL, Diana M (1998) Cannabinoids activate 
mesolimbic dopamine neurons by an action on cannabinoid CB1 receptors. Eur J Pharmacol 341:39-44. CrossRef Medline

González S, Valenti M, de Miguel R, Fezza F, Fernández-Ruiz J, Di Marzo V, Ramos JA (2004) Changes in endocannabinoid contents in rewardrelated brain regions of alcohol-exposed rats, and their possible relevance to alcohol relapse. Br J Pharmacol 143:455-464. CrossRef Medline

Grace AA, Bunney BS (1983) Intracellular and extracellular electrophysiology of nigral dopaminergic neurons-1. Identification and characterization. Neuroscience 10:301-315. CrossRef Medline

Hong S, Jhou TC, Smith M, Saleem KS, Hikosaka O (2011) Negative reward signals from the lateral habenula to dopamine neurons are mediated by rostromedial tegmental nucleus in primates. J Neurosci 31:11457-11471. CrossRef Medline

Ikemoto S, Bonci A (2014) Neurocircuitry of drug reward. Neuropharmacology 76:329-341. CrossRef Medline

Jalabert M, Bourdy R, Courtin J, Veinante P, Manzoni OJ, Barrot M, Georges F (2011) Neuronal circuits underlying acute morphine action on dopamine neurons. Proc Natl Acad Sci U S A 108:16446-16450. CrossRef Medline

Jhou TC, Geisler S, Marinelli M, Degarmo BA, Zahm DS (2009a) The mesopontine rostromedial tegmental nucleus: a structure targeted by the lateral habenula that projects to the ventral tegmental area of Tsai and substantia nigra compacta. J Comp Neurol 513:566-596. CrossRef Medline

Jhou TC, Fields HL, Baxter MG, Saper CB, Holland PC (2009b) The rostromedial tegmental nucleus (RMTg), a GABAergic afferent to midbrain dopamine neurons, encodes aversive stimuli and inhibits motor responses. Neuron 61:786-800. CrossRef Medline

Johnson SW, North RA (1992) Two types of neurone in the rat ventral tegmental area and their synaptic inputs. J Physiol 450:455-468. Medline

Koob GF, Le Moal M (2001) Drug addiction, dysregulation of reward, and allostasis. Neuropsychopharmacology 24:97-129. CrossRef Medline

Koob GF, Volkow ND (2010) Neurocircuitry of addiction. Neuropsychopharmacology 35:217-238. CrossRef Medline

Lecca S, Melis M, Luchicchi A, Ennas MG, Castelli MP, Muntoni AL, Pistis M (2011) Effects of drugs of abuse on putative rostromedial tegmental neurons, inhibitory afferents to midbrain dopamine cells. Neuropsychopharmacology 36:589-602. CrossRef Medline

Lecca S, Melis M, Luchicchi A, Muntoni AL, Pistis M (2012) Inhibitory inputs from rostromedial tegmental neurons regulate spontaneous activity of midbrain dopamine cells and their responses to drugs of abuse. Neuropsychopharmacology 37:1164-1176. CrossRef Medline

Ledent C, Valverde O, Cossu G, Petitet F, Aubert JF, Beslot F, Böhme GA, Imperato A, Pedrazzini T, Roques BP, Vassart G, Fratta W, Parmentier M (1999) Unresponsiveness to cannabinoids and reduced addictive effects of opiates in CB1 receptor knockout mice. Science 283:401-404. CrossRef Medline

Long JZ, Li W, Booker L, Burston JJ, Kinsey SG, Schlosburg JE, Pavón FJ, Serrano AM, Selley DE, Parsons LH, Lichtman AH, Cravatt BF (2009) Selective blockade of 2-arachidonoylglycerol hydrolysis produces cannabinoid behavioral effects. Nat Chem Biol 5:37-44. CrossRef Medline

Marinelli M, White FJ (2000) Enhanced vulnerability to cocaine selfadministration is associated with elevated impulse activity of midbrain dopamine neurons. J Neurosci 20:8876-8885. Medline

Marinelli M, Cooper DC, Baker LK, White FJ (2003) Impulse activity of midbrain dopamine neurons modulates drug-seeking behavior. Psychopharmacology 168:84-98. CrossRef Medline

Marsicano G, Wotjak CT, Azad SC, Bisogno T, Rammes G, Cascio MG, Hermann H, Tang J, Hofmann C, Zieglgänsberger W, Di Marzo V, Lutz B (2002) The endogenous cannabinoid system controls extinction of aversive memories. Nature 418:530-534. CrossRef Medline

Matsui A, Williams JT (2011) Opioid-sensitive GABA inputs from rostromedial tegmental nucleus synapse onto midbrain dopamine neurons. J Neurosci 31:17729-17735. CrossRef Medline

Melis M, Pistis M (2012) Hub and switches: endocannabinoid signalling in midbrain dopamine neurons. Philos Trans R Soc Lond B Biol Sci 367: 3276-3285. CrossRef Medline

Melis M, Camarini R, Ungless MA, Bonci A (2002) Long-lasting potentiation of GABAergic synapses in dopamine neurons after a single in vivo ethanol exposure. J Neurosci 22:2074-2082. Medline

Melis M, Pistis M, Perra S, Muntoni AL, Pillolla G, Gessa GL (2004a) Endocannabinoids mediate presynaptic inhibition of glutamatergic transmission in rat ventral tegmental area dopamine neurons through activation of CB1 receptors. J Neurosci 24:53-62. CrossRef Medline

Melis M, Perra S, Muntoni AL, Pillolla G, Lutz B, Marsicano G, Di Marzo V, Gessa GL, Pistis M (2004b) Prefrontal cortex stimulation induces 2-arachidonoyl-glycerol-mediated suppression of excitation in dopamine neurons. J Neurosci 24:10707-10715. CrossRef Medline

Melis M, Pillolla G, Perra S, Colombo G, Muntoni AL, Pistis M (2009) Electrophysiological properties of dopamine neurons in the ventral tegmental area of Sardinian alcohol-preferring rats. Psychopharmacology 201:471481. CrossRef Medline

Melis M, De Felice M, Lecca S, Fattore L, Pistis M (2013a) Sex-specific tonic 2 -arachidonoylglycerol signaling at inhibitory inputs onto dopamine neurons of Lister Hooded rats. Front Integr Neurosci 7:93. CrossRef Medline

Melis M, Scheggi S, Carta G, Madeddu C, Lecca S, Luchicchi A, Cadeddu F, Frau R, Fattore L, Fadda P, Ennas MG, Castelli MP, Fratta W, Schilstrom B, Banni S, De Montis MG, Pistis M (2013b) PPARalpha regulates cholinergic-driven activity of midbrain dopamine neurons via a novel mechanism involving alpha7 nicotinic acetylcholine receptors. J Neurosci 33:6203-6211. CrossRef Medline

Pan B, Wang W, Long JZ, Sun D, Hillard CJ, Cravatt BF, Liu QS (2009) Blockade of 2-arachidonoylglycerol hydrolysis by selective monoacylglycerol lipase inhibitor 4-nitrophenyl 4-(dibenzo[d][1,3] dioxol-5-yl(hydroxy)methyl) piperidine-1-carboxylate (JZL184) Enhances retrograde endocannabinoid signaling. J Pharmacol Exp Ther 331:591-597. CrossRef Medline

Paxinos G, Watson C (2007) The rat brain in stereotaxic coordinates, Ed 7. London: Elsevier Academic.

Piazza PV, Deroche-Gamonet V (2013) A multistep general theory of transition to addiction. Psychopharmacology 229:387-413. CrossRef Medline

Pitler TA, Alger BE (1994) Depolarization-induced suppression of GABAergic inhibition in rat hippocampal pyramidal cells: $G$ protein involvement in a presynaptic mechanism. Neuron 13:1447-1455. CrossRef Medline

Rezvani AH, Sexton H, Levin ED (2010) Persistent high alcohol consumption in alcohol-preferring $(\mathrm{P})$ rats results from a lack of normal aversion to alcohol. Alcohol Alcohol 45:219-222. CrossRef Medline

Rubio M, McHugh D, Fernández-Ruiz J, Bradshaw H, Walker JM (2007) Short-term exposure to alcohol in rats affects brain levels of anandamide, other $\mathrm{N}$-acylethanolamines and 2-arachidonoyl-glycerol. Neurosci Lett 421:270-274. CrossRef Medline

Stolerman I (1992) Drugs of abuse: behavioural principles, methods and terms. Trends Pharmacol Sci 13:170-176. CrossRef Medline

Vincent P, Armstrong CM, Marty A (1992) Inhibitory synaptic currents in rat cerebellar Purkinje cells: modulation by postsynaptic depolarization. J Physiol 456:453-471. Medline

Vinod KY, Yalamanchili R, Xie S, Cooper TB, Hungund BL (2006) Effect of chronic ethanol exposure and its withdrawal on the endocannabinoid system. Neurochem Int 49:619-625. CrossRef Medline

Vinod KY, Maccioni P, Garcia-Gutierrez MS, Femenia T, Xie S, Carai MA, Manzanares J, Cooper TB, Hungund BL, Colombo G (2012) Innate difference in the endocannabinoid signaling and its modulation by alcohol consumption in alcohol-preferring sP rats. Addict Biol 17:62-75. CrossRef Medline

Yoshida T, Uchigashima M, Yamasaki M, Katona I, Yamazaki M, Sakimura K, Kano M, Yoshioka M, Watanabe M (2011) Unique inhibitory synapse with particularly rich endocannabinoid signaling machinery on pyramidal neurons in basal amygdaloid nucleus. Proc Natl Acad Sci U S A 108: 3059-3064. CrossRef Medline 